\title{
Overweight and obesity among Ghanaian residents in The Netherlands: how do they weigh against their urban and rural counterparts in Ghana?
}

\author{
Charles Agyemang ${ }^{1, *}$, Ellis Owusu-Dabo ${ }^{2}$, Ank de Jonge ${ }^{3}$, David Martins ${ }^{4}$, \\ Gbenga Ogedegbe ${ }^{5}$ and Karien Stronks ${ }^{1}$ \\ 'Department of Social Medicine, Academic Medical Centre, University of Amsterdam, Meibergdreef 9, \\ 1105 AZ Amsterdam, The Netherlands: ${ }^{2}$ Department of Community Health, School of Medical Sciences, Kwame \\ Nkrumah University of Science \& Technology, Kumasi, Ghana: ${ }^{3}$ TNO Quality of Life, Leiden, The Netherlands: \\ ${ }^{4}$ Clinical Research Center, Charles R. Drew University, Los Angeles, CA, USA: ${ }^{5}$ Behavioral Cardiovascular \\ Health \& Hypertension Program, Division of General Medicine, Columbia University College of Physicians \& \\ Surgeons, New York, NY, USA
}

Submitted 8 January 2008: Accepted 7 July 2008: First published online 2 September 2008

\begin{abstract}
Objective: To investigate differences in overweight and obesity between firstgeneration Dutch-Ghanaian migrants in The Netherlands and their rural and urban counterparts in Ghana.

Design: Cross-sectional study.

Subjects: A total of 1471 Ghanaians (rural Ghanaians, $n$ 532; urban Ghanaians, $n$ 787; Dutch-Ghanaians, $n$ 152) aged $\geq 17$ years.

Main outcome measures: Overweight $\left(\mathrm{BMI} \geq 25 \mathrm{~kg} / \mathrm{m}^{2}\right)$ and obesity (BMI $\geq 30$ $\mathrm{kg} / \mathrm{m}^{2}$ ).

Results: Dutch-Ghanaians had a significantly higher prevalence of overweight and obesity (men $69 \cdot 1 \%$, women $79.5 \%$ ) than urban Ghanaians (men $22.0 \%$, women $50 \cdot 0 \%$ ) and rural Ghanaians (men 10.3\%, women 19.0\%). Urban Ghanaian men and women also had a significantly higher prevalence of overweight and obesity than their rural Ghanaian counterparts. In a logistic regression analysis adjusting for age and education, the odds ratios for being overweight or obese were $3 \cdot 10$ (95\% CI $1 \cdot 75,5 \cdot 48)$ for urban Ghanaian men and $19 \cdot 06$ (95\% CI 8.98, 40.43) for Dutch-Ghanaian men compared with rural Ghanaian men. Among women, the odds ratios for being overweight and obese were $3 \cdot 84$ (95\% CI 2.66, 5.53) for urban Ghanaians and 11.4 (95\% CI 5•97, 22.07) for Dutch-Ghanaians compared with their rural Ghanaian counterparts.

Conclusion: Our current findings give credence to earlier reports of an increase in the prevalence of overweight/obesity with urbanization within Africa and migration to industrialized countries. These findings indicate an urgent need to further assess migration-related factors that lead to these increases in overweight and obesity among migrants with non-Western background, and their impact on overweight- and obesity-related illnesses such as diabetes among these populations.
\end{abstract}

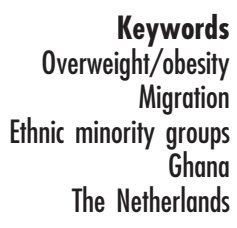

Obesity is now reaching epidemic proportions and is increasingly recognized as an important public health burden $^{(1,2)}$. Recent WHO global projections indicate that about 1.6 billion adults (age $\geq 15$ years) were overweight and at least some 400 million adults were obese in 2005 . WHO further projects that by 2015 , approximately $2 \cdot 3$ billion adults will be overweight and more than 700 million will be obese ${ }^{(3)}$. Once considered a problem only in wealthy countries, WHO estimates also indicate that the prevalence of overweight and obesity is now increasing dramatically in low-income countries. The increasing prevalence of obesity is worrying because epidemiological studies have consistently shown it to be associated with increased risks of morbidity, disability and mortality ${ }^{(4-11)}$. For example, obesity is a well-known risk factor for type 2 diabetes mellitus and is associated with some of the major risk factors for CVD, such as hypertension $^{(5,6)}$. Overweight and obesity (BMI $\geq 25 \mathrm{~kg} /$ $\mathrm{m}^{2}$ ) has been estimated to account for about $65-80 \%$ of new cases of type 2 diabetes ${ }^{(5)}$. 
In Western countries, overweight and obesity is highly prevalent in ethnic minority groups, particularly in women, as compared with the people of the host countries $^{(12-15)}$. The explanations for these high prevalence rates among ethnic minority people are speculative, as empirical studies underpinning such observations are rare. Understanding the mechanism underlying the increasing prevalence of overweight and obesity among ethnic minority people is crucial for appropriate intervention strategies for prevention. Earlier studies comparing various populations of African descent in diverse geographical settings found a positive gradient in the prevalence of CVD risk factors from rural Africa to urban North America ${ }^{(16-18)}$. Migration studies may therefore have the potential to increase our understanding about the increasing prevalence of overweight and obesity among these populations in Western countries. For example, comparison between first-generation migrants and their counterparts in their country of origin may help to provide important clues about the increasing prevalence of overweight and obesity among these populations in Western countries. However, migration studies on overweight and obesity are rare.

The main objective of the present paper was therefore to assess differences in overweight and obesity between first-generation Ghanaian migrants in The Netherlands and their counterparts living in rural and urban Ghana. Our prior hypothesis was that overweight and obesity would be substantially higher among Ghanaian residents in The Netherlands as compared with residents in urban and rural Ghana.

\section{Methods}

\section{Study area}

Urban and rural data for the present study were collected in the Ashanti region of Ghana. Ghana is situated on West Africa's Gulf of Guinea, only a few degrees north of the Equator with a total area of 238540 square kilometres. According to the Population Reference Bureau ${ }^{(19)}$, the total population in mid-2007 was about 23 million with an annual growth rate of $2 \cdot 3 \%$. The life expectancy was 58 years for men and 59 years for women. About $44 \%$ of the population live in urban while $56 \%$ live in rural areas.

The Netherlands data were collected in four cities: Amsterdam, Dordrecht, Rotterdam and The Hague. The majority of Ghanaians in The Netherlands originate from the Ashanti tribe in Ghana. They came to The Netherlands in the 1980s due to economic downturn in Ghana and Nigeria, where many were working(20). In 2003 there were approximately 18000 officially recorded Ghanaians in The Netherlands. However, there are a large number of undocumented Ghanaians in The Netherlands, which suggests that this number was underestimated. A more reliable estimate in 2000 was 40000 based on Ghanaians in The Netherlands who registered to vote at the Ghanaian embassy for the presidential elections in Ghana in $2000^{(20)}$.

\section{Study design}

\section{Data collection in Ghana}

Details of the study methods in Ghana have been published elsewhere ${ }^{(21,22)}$. In short, data were collected in the regional capital city (Kumasi) and four villages in the Ashanti region of Ghana between August and September 2004 among adults aged 18 years and above. In the city, six churches with different denominations, teachers from seven schools and two banks (one bank had four branches) were selected randomly from lists of churches, schools and banks. Because of financial constraints, four villages were selected based on the recommendations from local advisors. In the villages, following the local rules, the chiefs and elders were contacted in advance to obtain their permission. In each village, the elders fixed an appropriate date for the community and reminded them prior to the data collection date. To ensure that everybody in each village had an equal chance of being selected, measurements were restricted to every other house. The villages have no main water supply, and the main occupation is subsistence farming. Because only physical measurements were made, only verbal informed consent was sought from the subjects before measurements were taken. In all the churches, data collection was done in the church in a special room provided by the church leaders. The bank managers and school principals also provided special rooms where weight and height were measured. The participation rates were high in all sites. For example, among 122 bank workers, only one person refused to participate and none of the teachers refused to participate. The response rate in the churches ranged from $82 \%$ to $95 \%$. In all the villages, only two people present at the time of data collection refused his/her measurements to be taken.

\section{Data collection in The Netherlands}

In The Netherlands, a snowballing approach was used because of the difficulties in reaching this community. Leaders of three churches in three cities (Amsterdam, Dordrecht and Rotterdam) and one Ghanaian organization in The Hague were approached about the study. After discussions about the importance of the study, all leaders agreed to participate after consultations with their members. With leaders from each church and the organization, special dates were arranged for data collection by a trained Ghanaian nurse. At each site, all people present at the time agreed to have their measurements taken. About $98 \%$ of our study participants in The Netherlands originated from the Ashanti region of Ghana. In line with Dutch legislation, the study was approved by the Netherlands Organization for Health Research and 
Development and judged to need no further review by a medical ethics committee as participants were recruited on a volunteer basis and were not required to undergo clinical examination.

The target sample size was mostly determined by the resources available. However, it was also based on our power calculations that showed that this sample size would achieve reasonably precise estimates of the mean values of key risk factors and would detect differences of the expected magnitude between the groups.

\section{Measurements}

Weight was measured to the nearest $0 \cdot 1 \mathrm{~kg}$ after removal of shoes, jackets, heavier clothing and pocket contents (using an Electronic Korona Profimed scale, Germany) by trained staff. Height was measured without shoes with a measuring tape to the nearest $0.5 \mathrm{~cm}$. BMI was calculated as weight $(\mathrm{kg})$ divided by the square of height $\left(\mathrm{m}^{2}\right)$. Overweight and obesity were defined as BMI $\geq 25$ $\mathrm{kg} / \mathrm{m}^{2}$ and $\mathrm{BMI} \geq 30 \mathrm{~kg} / \mathrm{m}^{2}$, respectively ${ }^{(23)}$. In addition, information on demographics and education level was collected.

The Committee on Human Research Publication and Ethics, Kwame Nkrumah University of Science and Technology, Ghana approved the study protocols.

\section{Data analysis}

The $\chi^{2}$ test was used to assess differences in categorical variables. Continuous variables were analysed using $t$ tests. Differences in overweight/obesity were assessed by means of logistic regression analysis. All results from the logistic regression model are shown as odds ratios with corresponding $95 \%$ confidence intervals. All statistical tests were two-tailed and $P$ values $\leq 0 \cdot 05$ were considered statistically significant. All statistical analyses were performed using the SPSS for Windows statistical software package version $14 \cdot 0 \cdot 1$ (SPSS Inc., Chicago, IL, USA).

\section{Results}

Table 1 shows the characteristics of the study population. Among men, urban Ghanaians were younger and had a higher level of education compared with rural Ghanaians and Dutch-Ghanaians. The Dutch-Ghanaians were taller than the rural and urban Ghanaians. Urban Ghanaians and Dutch-Ghanaians were heavier than rural Ghanaians. Among women, rural Ghanaians were older and less educated compared with urban Ghanaians and Dutch-Ghanaians. Rural Ghanaian women were shorter and lighter than both urban Ghanaians and Dutch-Ghanaians.

Figures 1(a) and 1(b) show mean BMI by locality in men and women. In both men and women, there were positive gradients in mean BMI from rural Ghana to

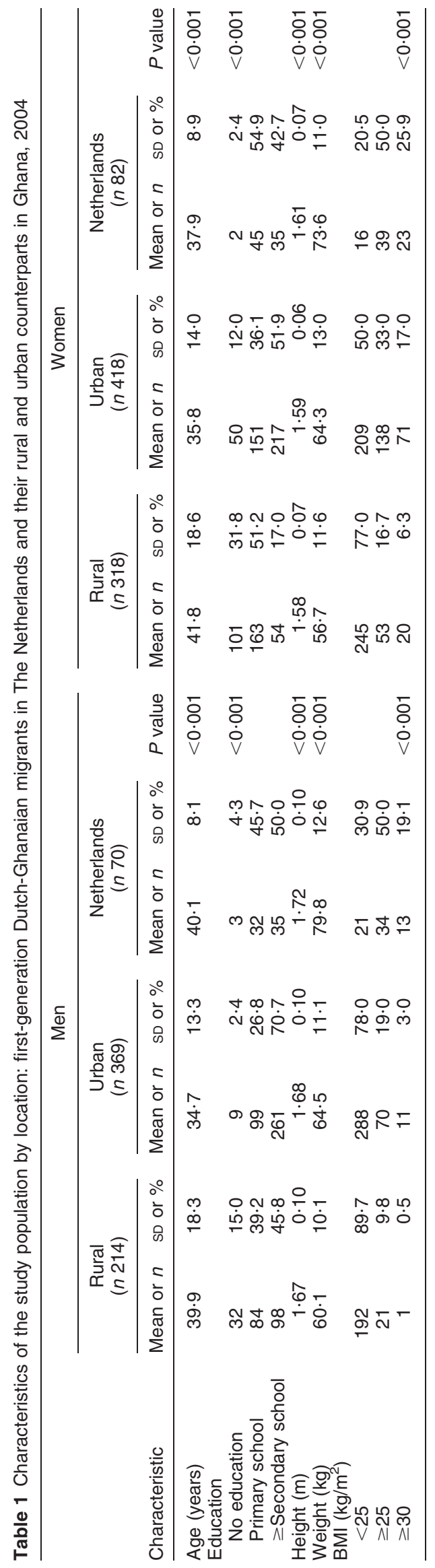




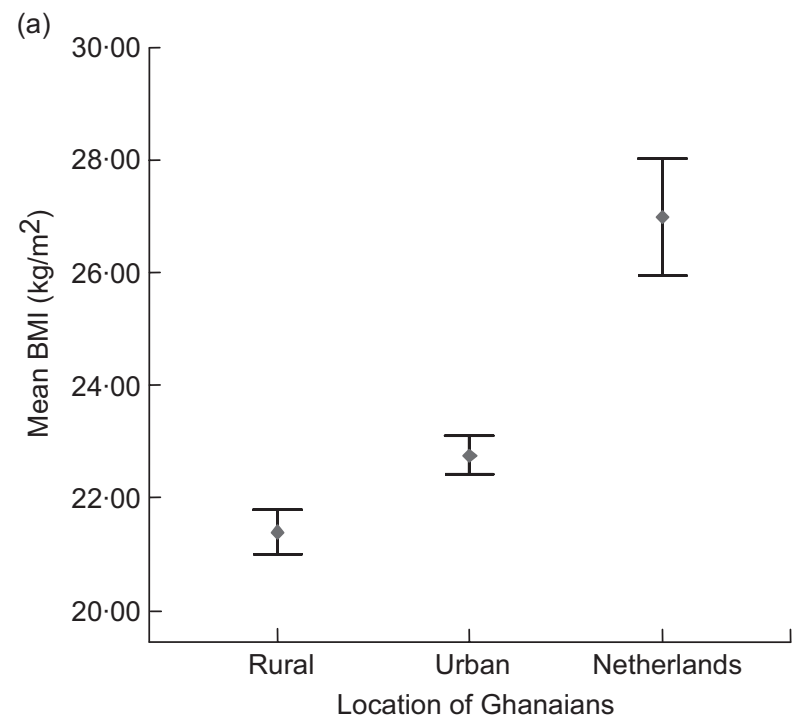

(a)

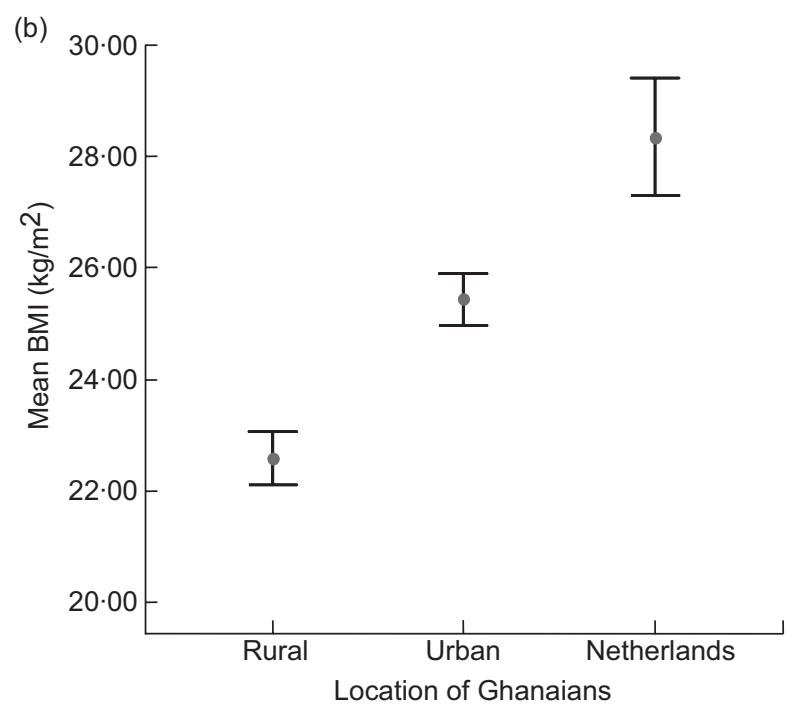

(b)

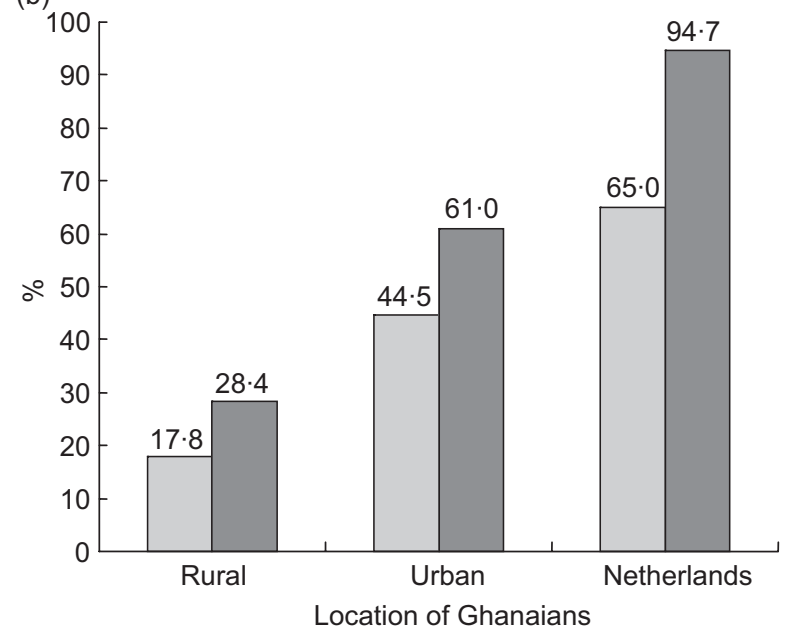

Fig. 2 Overweight/obesity $\left(\mathrm{BMI} \geq 25 \mathrm{~kg} / \mathrm{m}^{2}\right)$ by age group ( $\square,<40$ years; $\square, \geq 40$ years) and locality in men (a) and women (b): first-generation Dutch-Ghanaian migrants in The Netherlands and their rural and urban counterparts in Ghana, 2004

Fig. 1 Mean BMI by locality in men (a) and women (b): first generation Dutch-Ghanaian migrants in The Netherlands and their rural and urban counterparts in Ghana, 2004

urban Ghana and to The Netherlands. The DutchGhanaian men and women had higher BMI than their urban Ghanaian and rural Ghanaian counterparts. The urban Ghanaian men and women also had higher BMI than their rural Ghanaian counterparts.

Figures 2(a) and 2(b) show the prevalence rates of overweight and obesity (BMI $\geq 25 \mathrm{~kg} / \mathrm{m}^{2}$ ) by locality and age group. Among men, the prevalence of overweight/ obesity was higher in the older age group than the younger age group in all localities. However, the rates were higher in both younger and older Dutch-Ghanaian men $(50 \cdot 0 \%$ and $84 \cdot 2 \%)$ than their urban Ghanaian $(14 \cdot 1 \%$ and $39 \cdot 2 \%)$ and rural Ghanaian counterparts $(5 \cdot 6 \%$ and $16 \cdot 7 \%)$. Similarly, a higher prevalence of overweight and obesity was also found among younger and older Dutch-Ghanaian women $(65 \cdot 0 \%$ and $94.7 \%)$

than in their urban Ghanaian $(44.5 \%$ and $61.0 \%)$ and rural Ghanaian counterparts (17.8\% and $28 \cdot 4 \%)$.

Table 2 shows adjusted odds ratios and 95\% confidence intervals of overweight and obesity by locality in men and women. In an age-adjusted model, the Dutch-Ghanaian men were 18.8 times and urban Ghanaian men were 3.3 times more likely than rural Ghanaian men to be overweight or obese. Further adjustment for education did not have much influence on the differences. Among women, the Dutch-Ghanaians were $12 \cdot 3$ times and urban Ghanaians were $4 \cdot 1$ times more likely than rural Ghanaians to be overweight or obese. Further adjustment for educational level attenuated the differences slightly, but the Dutch-Ghanaians were still 11.5 times and urban Ghanaian $3 \cdot 8$ times more likely than their rural Ghanaian counterparts to be overweight or obese. 
Table 2 Adjusted odds ratios and $95 \%$ confidence intervals of overweight/obesity $\left(\mathrm{BMI} \geq 25 \mathrm{~kg} / \mathrm{m}^{2}\right)$ by location in men and women: firstgeneration Dutch-Ghanaian migrants in The Netherlands and their rural and urban counterparts in Ghana, 2004

\begin{tabular}{|c|c|c|c|c|c|c|c|c|}
\hline & \multicolumn{4}{|c|}{ Men } & \multicolumn{4}{|c|}{ Women } \\
\hline & \multicolumn{2}{|c|}{ Model I } & \multicolumn{2}{|c|}{ Model II } & \multicolumn{2}{|c|}{ Model I } & \multicolumn{2}{|c|}{ Model II } \\
\hline & OR & $95 \% \mathrm{Cl}$ & OR & $95 \% \mathrm{Cl}$ & OR & $95 \% \mathrm{Cl}$ & OR & $95 \% \mathrm{Cl}$ \\
\hline Rural Ghanaian & 1.00 & - & 1.00 & - & 1.00 & - & $1 \cdot 00$ & - \\
\hline Urban Ghanaian & $3 \cdot 33$ & $1 \cdot 91,5 \cdot 80$ & $3 \cdot 10$ & $1 \cdot 75,5 \cdot 48$ & 4.08 & $2 \cdot 87,5 \cdot 81$ & $3 \cdot 84$ & $2 \cdot 66,5 \cdot 53$ \\
\hline Dutch-Ghanaian & $18 \cdot 76$ & $8 \cdot 91,39 \cdot 48$ & $19 \cdot 06$ & $8 \cdot 98,40 \cdot 43$ & $12 \cdot 34$ & $6 \cdot 45,23 \cdot 61$ & $11 \cdot 48$ & $5 \cdot 97,22 \cdot 07$ \\
\hline
\end{tabular}

Model I adjusted for age; Model II adjusted for age plus education.

\section{Discussion}

The main purpose of the present study was to assess differences in overweight and obesity between first-generation Ghanaian residents in The Netherlands and their Ghanaian counterparts living in rural and urban Ghana. Our findings clearly indicate that the prevalence of overweight and obesity is much higher among the DutchGhanaians than among their urban and rural counterparts in Ghana. The urban Ghanaians also have a higher prevalence of overweight and obesity than their rural counterparts. These differences persisted even after differences in educational level had been taken into account.

This is one of the few studies that have compared differences in overweight and obesity among firstgeneration migrants with their counterparts from the same region of their country of birth. Reasons for the increasing prevalence of overweight and obesity among ethnic minority groups have been speculative since empirical studies underpinning such observations are rare. Our present study provides a new insight into the possible role of migration-related factors on overweight and obesity in Western countries. The huge differences found between the first-generation Ghanaian residents in The Netherlands and their counterparts in urban and rural Ghana clearly indicate that environmental factors are at play, and suggest the need to tackle overweight and obesity among migrant populations living in Western countries. It also provides an important foundation for further studies to determine migrationrelated lifestyle changes and factors that result in increases in body sizes among these populations in Western countries.

Cultural perceptions regarding overweight and obesity may also play a role in the increasing prevalence of overweight and obesity among migrant populations. In most parts of Africa, being overweight or obese was and still is, at least in some part, associated with prestige, happiness and good healthy living, especially in women $^{(24,25)}$. It has been reported that, traditionally, Ghanaians in general associate fatness with beauty ${ }^{(26)}$. It has also been documented that Ghanaian men in general prefer overweight and obese women to thin ones ${ }^{(26)}$ although recent evidence suggests that these purported perceptions are no longer the case ${ }^{(27)}$. Many Ghanaians came to The Netherlands in the 1980s, at a time when these perceptions were very strong. It is possible that they have held on to these perceptions in The Netherlands, which might contribute to the high rates of overnutrition and subsequently higher prevalence of overweight and obesity found among this group in The Netherlands. This, indeed, requires further studies.

Our findings have important implications for healthcare delivery not only for The Netherlands but also other Western countries such as the UK with large proportions of migrants. The risk of hypertension is up to five times higher among obese people than among people of normal weight ${ }^{(28)}$. Obesity is also closely related to type 2 diabetes $^{(29,30)}$; it is reported ${ }^{(30)}$ that about $90 \%$ of individuals who develop type 2 diabetes have BMI higher than $23.0 \mathrm{~kg} / \mathrm{m}^{2}$. The strong relationship between obesity and hypertension and diabetes among populations of African descent has been well described ${ }^{(12,16-18)}$. Although there is no information on obesity-related illnesses such as type 2 diabetes and hypertension among Ghanaian residents in The Netherlands, a recent report indicates that the incidence of malignant hypertension and related renal complications is higher in African-descent people (mainly Ghanaians and Nigerians) in Amsterdam than in white Dutch people ${ }^{(31)}$. The prevalence of overweight and obesity found among the Ghanaian population in The Netherlands exceeds the prevalence rates reported among their white Dutch male (overweight $40 \cdot 2 \%$ and obesity $14 \cdot 3 \%$ ) and female (overweight $34 \cdot 2 \%$ and obesity $15 \cdot 3 \%$ ) counterparts ${ }^{(13)}$, and this may contribute, at least in part, to the higher incidence of malignant hypertension and related renal complications reported among this group in The Netherlands ${ }^{(31)}$. Given the high prevalence of overweight and obesity among this population in The Netherlands, there is a strong case to study this population further to assess the impact of overweight- and obesity-related illnesses among this population in The Netherlands. Left unchecked, the increasing prevalence of overweight and obesity among these populations may take its toll as chronic diseases with huge consequences for these communities and the health-care services. 
Our findings also show a higher prevalence of overweight and obesity among urban Ghanaians than their rural counterparts. This is consistent with recent studies in West African countries ${ }^{(32,33)}$. Our study also confirms the earlier findings of a positive gradient in CVD risk factors from less developed to highly developed communities $^{(16-18)}$. Urbanization is associated with the adoption of lifestyles commonly referred to as 'Westernization', the consequence of which is the increased consumption of energy-dense foods and refined sugars complemented by less energy-demanding jobs in the urban centres ${ }^{(34-37)}$. Urbanization has also been associated with increased television ownership and viewing, as well as changes in traditional food preparation and the adoption of unhealthy eating habits including increased consumption away from home ${ }^{(38)}$. With increasing economic development in urban areas in Ghana, many urban Ghanaians have cheap means of transport. Fast-food chains are also on the increase. All of this may contribute to the higher prevalence of overweight and obesity in urban Ghana. The increasing prevalence of overweight and obesity comes with a rise in several overweight- and obesityrelated illnesses ${ }^{(39-41)}$. Recent compiled data in Ghana, for example, clearly indicate that the prevalence of diabetes $^{(42,43)}$ and cardiovascular risk factors such as hypertension $^{(12,13,44-46)}$ are correspondingly on the increase. Ghana, like many low-income countries, is now faced with the health threat of non-communicable diseases while still battling with the unfinished agendas of communicable diseases.

In 2003, the World Health Assembly adopted the Global Strategy on Diet, Physical Activity, and Health, which targets lifestyle modifications that can combat the increase in non-communicable diseases ${ }^{(47)}$. The WHO also issued objectives for low-income countries regarding healthy living. The present findings clearly indicate that there is a need for preventive measures to encourage and facilitate physical activity and healthy eating to control and prevent overweight and obesity in urban Ghana, in line with the WHO objectives.

There are limitations and strengths in our study. First, the differential sample techniques may bias our study conclusion. The urban Ghana sample, for example, was based on teachers, bank workers and church goers, whereas the Netherlands sample was based on churches and one community organization. Although this approach was used to ensure that people from different social and religious backgrounds were represented, it is possible that some people who did not fall into any of these groups may have been omitted, which may affect the study conclusions. However, most Ghanaians who originate from the Ashanti region are Christians and attend church regularly in both Ghana and The Netherlands. In addition, none of the people present at the time of measurement in The Netherlands refused to participate. Furthermore, the prevalence of overweight and obesity was consistently high across all churches and the one organization in all four cities. Second, our socio-economic indicator was based on educational level only and there was no information on lifestyle factors, which limits our ability to assess the possible determinants of obesity in different localities. Furthermore, we had no information on socio-economic circumstances and lifestyle factors prior to migration to The Netherlands. It is possible that the better-off Ghanaians migrated to The Netherlands, and perhaps were, given the phase of economic development in Ghana, more prone to develop overweight and obesity. The higher height of the DutchGhanaians may reflect this possibility. Nevertheless, many of the Dutch-Ghanaians first migrated to Nigeria before coming to The Netherlands due to economic hardship in Ghana in the $1980 \mathrm{~s}^{(20)}$. It is also possible that they benefited from the nutritional richer environment in Nigeria at the time, which may explain the higher height found among this group in The Netherlands. Future studies should assess the possible factors that may contribute to these locality differentials. Third, the sample of the Ghanaians in The Netherlands was relatively small compared with their counterparts in Ghana. Nevertheless, notwithstanding these limitations, the findings provide important information about the possible role of migration-related factors and their impact on the overweight and obesity pandemic among migrant populations in Western countries, and provide an important foundation for further studies. It is also one of the few studies that have compared overweight and obesity differences between first-generation migrants living in a Western country and their counterparts living in urban and rural settings from the same region of their country of origin.

\section{Conclusion}

Our findings demonstrate that the prevalence of overweight and obesity is overly high among first-generation Ghanaian residents in The Netherlands compared with their urban and rural Ghanaian counterparts in Ghana. These findings clearly indicate an urgent need to further assess migration-related factors that lead to these increases in overweight and obesity, and their impact on related illnesses such as diabetes and cardiovascular risk factors among this population in The Netherlands. Such information is essential for designing appropriate interventions for prevention.

The high prevalence of overweight and obesity among urban Ghanaian dwellers may contribute to the recently reported increases in diabetes and CVD in urban Ghana. Further increases in overweight and obesity will be seriously detrimental to the already overburdened healthcare resources in Ghana. Preventive measures are needed to control and prevent overweight and obesity in urban 
Ghana. Implementation and evaluation of the WHO directives will be a good starting point ${ }^{(42)}$.

\section{Acknowledgements}

\section{Conflict of interest: None.}

Sources of funds: This project was supported by the Health Research and Development Council of the Netherlands (ZonMw). C.A. was supported by a VENI fellowship (grant number 916.76.130) awarded by the Board of the Council for Earth and Life Sciences (ALW) of the Netherlands Organisation for Scientific Research (NWO).

Author contributions: C.A., E.O.-D, A.d.J. and K.S. conceived and designed this study. C.A. and A.d.J. did the statistical analysis. C.A. wrote the first draft of the paper and all co-authors commented on the draft, with major contributions from E.O.-D., A.d.J., D.M., G.O. and K.S. All other authors provided comments and approved the final manuscript.

Acknowledgements: We thank all the nurses, the study participants and the community leaders for making this study possible. We are also grateful to Miss Betty Kusi for recruiting participants and taking measurements in the various places in The Netherlands. We also thank Dr Mary Nicolaou for providing useful comments on an earlier draft.

\section{References}

1. World Health Organization (2000) Obesity: Preventing and Managing the Global Epidemic. Report of a WHO Consultation. WHO Technical Report Series no. 894. Geneva: WHO; available at http://whqlibdoc.who.int/trs/ WHO_TRS_894.pdf

2. Swinburn B, Gill T \& Kumanyika S (2005) Obesity prevention: a proposed framework for translating evidence into action. Obes Rev 6, 23-33.

3. World Health Organization (2006) The World Health Report 2006: Working Together for Health. Geneva: WHO.

4. Visscher TL \& Seidell JC (2001) The public health impact of obesity. Annu Rev Public Health 22, 355-375.

5. Seidell JC (1997) Time trends in obesity: an epidemiological perspective. Horm Metab Res 29, 155-158.

6. Field AE, Coakley EH, Must A, Spadano JL, Laird N, Dietz WH, Rimm E \& Colditz GA (2001) Impact of overweight on the risk of developing common chronic diseases during a 10-year period. Arch Intern Med 161, 1581-1586.

7. Ferrannini E (1995) Physiological and metabolic consequences of obesity. Metabolism 44, Suppl. 3, S15-S17.

8. Stern M (1995) Epidemiology of obesity and its link to heart disease. Metabolism 44, Suppl. 3, S1-S3.

9. Bjorntorp P (1995) Endocrine abnormalities in obesity. Metabolism 44, Suppl. 3, S21-S30.

10. Burton BT, Foster WR, Hirsch J \& Vanitallie TB (1998) Health implications of obesity: NIH consensus development conference. Int J Obes Relat Metab Disord 22, 39-43.

11. Deslypere JP (1995) Obesity and cancer. Metabolism 44, Suppl. 3, S24-S27.

12. Agyemang C \& Bhopal R (2003) Is the blood pressure of people from African origin adults in the UK higher or lower than that in European origin white people? A review of cross-sectional data. J Hum Hypertens 17, 523-534.

13. Agyemang C, Bindraban N, Mairuhu G, Montfrans G, Koopmans R \& Stronks K (2005) Prevalence, awareness, treatment, and control of hypertension among Black
Surinamese, South Asian Surinamese and White Dutch in Amsterdam, The Netherlands: the SUNSET study. J Hypertens 23, 1971-1977.

14. Misra A \& Ganda OP (2007) Migration and its impact on adiposity and type 2 diabetes. Nutrition 23, 696-708.

15. Kumar BN, Meyer HE, Wandel M, Dalen I \& HolmboeOttesen G (2006) Ethnic differences in obesity among immigrants from developing countries, in Oslo, Norway. Int J Obes (Lond) 30, 684-690.

16. Cooper RS, Rotimi CN, Kaufman JS, Owoaje EE, Fraser H, Forrester T, Wilks R, Riste LK \& Cruickshank JK (1997) Prevalence of NIDDM among populations of the African diaspora. Diabetes Care 20, 343-348.

17. Luke A, Durazo-Arvizu R, Rotimi C, Prewitt TE, Forrester T, Wilks R, Ogunbiyi OJ, Schoeller DA, McGee D \& Cooper RS (1997) Relation between body mass index and body fat in black population samples from Nigeria, Jamaica, and the United States. Am J Epidemiol 145, 620-628.

18. Cooper R, Rotimi C, Ataman S et al. (1997) Hypertension prevalence in seven populations of African origin. Am J Public Health 87, 160-168.

19. Population Reference Bureau (2008) Demographic and Health Highlights of Ghana. http://www.prb.org/Countries/ Ghana.aspx (accessed January 2008).

20. Nimako K (2000) De Ghanese gemeenschap: Van migranten tot etnische minderheid. In Afrikanen in Nederland, pp. 165-181 [I van Kessel and $\mathrm{N}$ Tellegen, editors]. Amsterdam: KIT.

21. Agyemang C (2006) Rural and city differences in blood pressure and hypertension in Ghana, West Africa. Public Health 120, 525-533.

22. Agyemang C, Bruijnzeels MA \& Owusu-Dabo E (2006) Factors associated with hypertension awareness, treatment, and control in Ghana, West Africa. J Hum Hypertens 20, 67-71.

23. WHO Expert Consultation (2004) Appropriate body-mass index for Asian populations and its implications for policy and intervention strategies. Lancet 363, 157-163.

24. Holdsworth M, Gartner A, Landais E, Maire B \& Delpeuch F (2004) Perceptions of healthy and desirable body size in urban Senegalese women. Int J Obes Relat Metab Disord 28, 1561-1568.

25. Siervo M, Grey P, Nyan OA \& Prentice AM (2005) Urbanization and obesity in The Gambia: a country in the early stages of the demographic transition. Eur J Clin Nutr 60, $455-463$.

26. Amoah AG (2003) Sociodemographic variations in obesity among Ghanaian adults. Public Health Nutr 6, 751-757.

27. Duda RB, Jumah NA, Hill AG, Seffah J \& Biritwum R (2006) Interest in healthy living outweighs presumed cultural norms for obesity for Ghanaian women. Health Qual Life Outcomes $\mathbf{4}, 44$.

28. Wolf HK, Tuomilehto J, Kuulasmaa K, Domarkiene S, Cepaitis Z, Molarius A, Sans S, Dobson A, Keil U \& Rywik S (1997) Blood pressure levels in the 41 populations of the WHO MONICA project. J Hum Hypertens 11, 733-742.

29. Stevens J, Couper D, Pankow J, Folsom AR, Duncan BB, Nieto FJ, Jones D \& Tyroler HA (2001) Sensitivity and specificity of anthropometrics for the prediction of diabetes in a biracial cohort. Obes Res $9,696-705$.

30. Wannamethee SG \& Shaper AG (1999) Weight change and duration of overweight and obesity in the incidence of type 2 diabetes. Diabetes Care 22, 1266-1272.

31. van den Born BJ, Koopmans RP, Groeneveld JO \& van Montfrans GA (2006) Ethnic disparities in the incidence, presentation and complications of malignant hypertension. J Hypertens 24, 2299-2304.

32. Fezeu LK, Assah FK, Balkau B, Mbanya DS, Kengne AP, Awah PK \& Mbanya JC (2008) Ten-year changes in central obesity and BMI in rural and urban Cameroon. Obesity (Silver Spring) 16, 1144-1147. 
33. Abubakari AR, Lauder W, Agyemang C, Jones M, Kirk A \& Bhopal RS (2008) Prevalence and time trends in obesity among adult West African populations: a meta-analysis. Obes Rev 9, 297-311.

34. Popkin BM (2006) Global nutrition dynamics: the world is shifting rapidly toward a diet linked with noncommunicable diseases. Am J Clin Nutr 84, 289-298.

35. Prentice A \& Webb F (2006) Obesity amidst poverty. Int J Epidemiol 35, 24-30.

36. Yusuf S, Reddy S, Ounpuu S \& Anand S (2001) Global burden of cardiovascular diseases: Part I: general considerations, the epidemiologic transition, risk factors, and impact of urbanization. Circulation 104, 2746-2753.

37. Prentice AM (2006) The emerging epidemic of obesity in developing countries. Int J Epidemiol 35, 93-99.

38. Eckel RH (2003) Obesity: Mechanisms and Clinical Management. Philadelphia, PA: Lippincott Williams \& Wilkins.

39. Wild S, Roglic G, Green A, Sicree R \& King H (2004) Global prevalence of diabetes: estimates for the year 2000 and projections for 2030. Diabetes Care 27, 1047-1053.

40. Haslam DW \& James WP (2005) Obesity. Lancet 366, 1197-1209.

41. Ezzati M, Lopez AL, Danaei G, Rodjers A \& Mathers CD (2004) Comparative Quantification of Health Risks: Global and Regional Burden of Disease Attributable to Selected Major Risk Factors. Geneva: WHO.

42. Amoah AG, Owusu SK \& Adjei S (2002) Diabetes in Ghana: a community based prevalence study in Greater Accra. Diabetes Res Clin Pract 56, 197-205.

43. Osei K, Schuster DP, Amoah AG \& Owusu SK (2003) Diabetes in Africa. Pathogenesis of type 1 and type 2 diabetes mellitus in sub-Saharan Africa: implications for transitional populations. J Cardiovasc Risk 10, 85-96.

44. Agyemang C \& Owusu-Dabo E (2008) Prehypertension in the Ashanti region of Ghana, West Africa: an opportunity for early prevention of clinical hypertension. Public Health 122, 19-24.

45. Cappuccio FP, Micah FB, Emmett L, Kerry SM, Antwi S, Martin-Peprah R, Phillips RO, Plange-Rhule J \& Eastwood JB (2004) Prevalence, detection, management, and control of hypertension in Ashanti, West Africa. Hypertension $\mathbf{4 3}$ $1017-1022$.

46. Amoah AG (2003) Hypertension in Ghana: a crosssectional community prevalence study in greater Accra. Ethn Dis 13, Summer, 310-315.

47. World Health Organization (2003) Diet, Nutrition and the Prevention of Chronic Diseases. Report of a Joint WHO/FAO Expert Consultation. WHO Technical Report Series no. 916. Geneva: WHO. 